\title{
Case report: Anesthetic management for sequen- tial Cesarean delivery and laminectomy
}

\author{
[Présentation de cas: Anesthésie pour accouchement par césarienne suivi d’une \\ laminectomie]
}

Arif Al-areibi MD MSc, Lynn Coveney FRCPC, Sudha Singh FRCPC, Sandra Katsiris FRCPC

Purpose: To describe the anesthetic considerations for a nearterm parturient with progressive cauda equina syndrome who required Cesarean delivery followed immediately by decompression lumbar discectomy and laminectomy in the prone position.

Clinical features: A 33-yr-old woman presented at 35 weeks gestation with severe L5-SI disc herniation causing motor and sensory neuronal dysfunction in the lower limbs accompanied by bowel and bladder dysfunction. After urgent multidisciplinary consultations, a decision was made to proceed with general anesthesia for Cesarean delivery in the supine position with left uterine displacement, followed immediately thereafter by L5-SI discectomy and laminectomy in the prone position. Anesthesia concerns included the risks of hemorrhage from the combined surgeries and upper airway edema from the prone position, and the physiologic changes of pregnancy. The surgeries proceeded without complication, and both mother and baby recovered uneventfully.

Conclusion: With a multidisciplinary approach, two surgeries in two different positions with unique anesthetic considerations were performed safely under general anesthesia in advanced pregnancy in a parturient with cauda equina syndrome.

CAN J ANESTH 2007 / 54: 6 / pp 471-474

Objectif: Décrire les considérations anesthésiques concernant une parturiente presqu'à terme présentant un syndrome de la queue de cheval et nécessitant un accouchement par césarienne immédiatement suivi par une discectomie lombaire de décompression et une laminectomie en position de décubitus ventral.

Éléments cliniques : Une femme de 33 ans s'est présentée à 35 semaines de grossesse avec une hernie discale L5-SI grave causant un dysfonctionnement moteur et sensori-neuronal des membres inférieurs ainsi que des troubles intestinaux et de la vessie. Suite à des consultations multidisciplinaires urgentes, il a été décidé de procéder à une anesthésie générale pour l'accouchement par césarienne en position de décubitus dorsal avec déplacement utérin gauche. La césarienne a été immédiatement suivie par une discectomie L5-SI et une laminectomie en position de décubitus ventral. Le risque hémorragique des chirurgies combinées, l'œdème des voies aériennes supérieures, ainsi que les changements physiologiques de la grossesse constituent les préoccupations anesthésiques. Les chirurgies se sont déroulées sans complication, et la mère et le bébé se sont rétablis sans difficulté.

Conclusion : Grâce à une approche multidisciplinaire, deux chirurgies en deux positions différentes présentant des considérations anesthésiques spécifiques ont été effectuées en toute sécurité sous anesthésie générale chez une parturiente proche du terme souffrant du syndrome de la queue de cheval.

$\mathrm{F}$ EW cases of cauda equina syndrome during pregnancy have been reported in the literature. ${ }^{1-5}$ Most of these cases involved cauda equina syndrome in parturients early in pregnancy (before 24 weeks of gestation.). Recently, Brown and Brookfield reported performing a Cesarean delivery and laminectomy in a parturient who was eight months pregnant. ${ }^{5}$ Our case report is the first to discuss the anesthetic management of a parturient at 35 weeks gestation who underwent a Cesarean delivery followed by laminectomy in the prone position under the same general anesthetic for cauda equina syndrome. The patient gave written consent for publication of this information.

From the Department of Anesthesia and Perioperative Medicine, London Health Science Centre, London, Ontario, Canada. Address correspondence to: Dr. Arif Al-areibi, Department of Anesthesiology, University

Hospital, London, Ontario N6A 5A5, Canada. Phone: 519-685-8500, ext. 33283; Fax: 519-663-3079. E-mail: aareibi@yahoo.com Accepted for publication November 7, 2006.

Revision accepted March 1, 2007.

Final revision accepted March 10, 2007. 


\section{Case report}

A 33-yr-old multiparous woman with a one-year history of chronic lower back pain presented at 35 weeks gestation with a three-day history of severe back pain radiating to her right lower limb. She also had urinary incontinence, constipation and perineal anesthesia for one day prior to admission. Her past medical history was unremarkable except for mild, exercise-induced bronchial asthma. Her pregnancy was otherwise uncomplicated. She had two previous normal pregnancies and vaginal deliveries and a previous general anesthetic was uneventful.

Physical examination revealed a body weight of $75 \mathrm{~kg}$ and a height of $165 \mathrm{~cm}$. The patient had a Mallampati class I airway, full range of neck movement and an adequate thyromental distance. The cardiovascular and respiratory examinations were unremarkable. Neurological examination revealed weakness of the right lower limb muscles with loss of sensation in the S1 nerve root distribution.

Routine hematological investigations were normal, and the obstetrical ultrasound imaging was consistent with a normal pregnancy at 35 weeks gestation. The magnetic resonance imaging scan demonstrated a central disc herniation at the L5-S1 level, which completely obliterated the spinal canal (Figure).

The neurosurgeon, obstetrician, anesthesiologist, and neonatologist urgently reviewed the case. After discussion with the patient, a decision was made to perform Cesarean delivery followed immediately by laminectomy and discectomy in the prone position under general anesthesia.

The patient was transferred to the operating room where standard non-invasive monitors were applied. An arterial line, two large bore in cannulae, and a Foley catheter were inserted. Packed red blood cells were available in the room. Aspiration prophylaxis with $30 \mathrm{~mL}$ of oral sodium citrate was given to the patient. She was then positioned supine with left uterine displacement. The abdomen was prepared and draped for the Cesarean delivery by the obstetrical team. Preoxygenation was followed by a rapid sequence induction of anesthesia using propofol 180 $\mathrm{mg} i v$ followed by succinylcholine $120 \mathrm{mg} i \mathrm{v}$. Cricoid pressure was maintained during induction and the patient's airway was secured with a standard endotracheal tube using direct laryngoscopy. After verifying correct endotracheal tube position by capnography and chest auscultation, anesthesia was maintained with sevoflurane $1 \mathrm{MAC}$ and $100 \%$ oxygen. The infant was delivered with Apgar scores of 8 and 9, at one and five minutes respectively. After delivery of the infant, sevoflurane was reduced to $0.7 \mathrm{MAC}, 60 \%$ nitrous

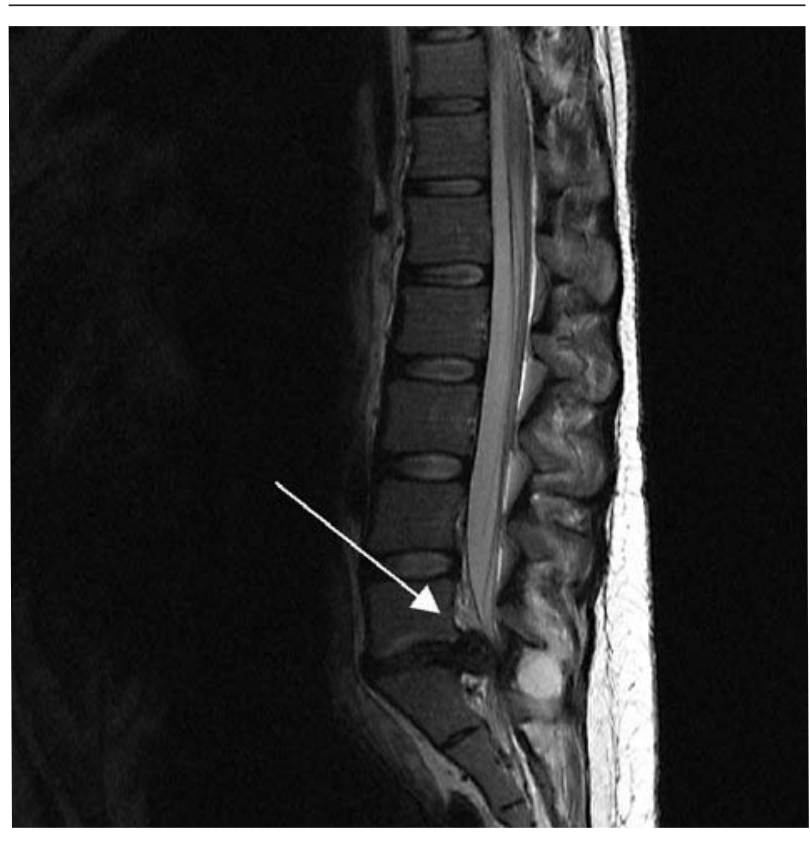

$\overline{\text { FIGURE Magnetic resonance imaging scan of lumbar spine }}$ demonstrates severe disc displacement at the L5-S1 level.

oxide was added and oxytocin was given. An upper body warming blanket and a fluid warmer were used to maintain normothermia. The Cesarean delivery lasted for approximately one hour and was uneventful, except for mild uterine atony which responded to uterine massage and oxytocin. The estimated blood loss was $500 \mathrm{~mL}$.

Rocuronium $30 \mathrm{mg} i v$ and fentanyl $100 \mu \mathrm{g} i \mathrm{v}$ were administered prior to turning the patient prone with appropriate padding, and careful checking for pressure points. The endotracheal tube was re-checked for correct position by chest auscultation and for secure taping before and after positioning. An L5-S1 laminectomy was performed uneventfully over the next two hours. Cumulative doses of fentanyl $200 \mu \mathrm{g}$ iv and morphine $4 \mathrm{mg}$ iv were administered during the combined procedure, while a continuous infusion of oxytocin was maintained throughout the laminectomy. The estimated blood loss from the two procedures was $700 \mathrm{~mL}$ and the patient received a total of $2.5 \mathrm{~L}$ of isotonic crystalloid and $50 \mathrm{U}$ of oxytocin. There were no episodes of systemic hypotension, arrhythmia, hypercarbia or oxygen desaturation, and ventilatory pressures were not elevated in the prone position. Upon completion of surgery residual neuromuscular block was reversed with neostigmine $2.5 \mathrm{mg} i v$ and glycopyrrolate $0.4 \mathrm{mg} i \mathrm{v}$, and the patient was turned 
supine, at which point direct laryngoscopy confirmed a normal airway. The patient's trachea was extubated when she was awake and responsive, and the patient was subsequently transferred to the postanesthetic care unit where she recovered uneventfully over the next three hours.

Morphine patient-controlled analgesia was initiated for postoperative analgesia. The infant was monitored in the neonatal intensive care unit for $24 \mathrm{hr}$ and then discharged to the mother on the second day; both patients were discharged home on the sixth postoperative day. While the mother had residual bladder dysfunction, she regained full motor and sensory function of the lower limbs by the time of hospital discharge.

\section{Discussion}

We have described the anesthetic management of sequential Cesarean delivery followed by urgent decompressive laminectomy in a 35-week-pregnant woman with cauda equina syndrome, secondary to severe lumbar disc herniation. The anesthetic considerations included two urgent surgeries, two different positions including the prone position, the physiological changes of pregnancy including the potential for difficult airway, a premature and viable fetus, and the potential for severe intraoperative bleeding.

Cauda equina syndrome secondary to lumbar disc herniation is a surgical emergency. A poor prognosis is correlated with the length of time from onset of symptoms to surgical decompression. The patient in this case had a severe L5-S1 disc herniation causing motor and sensory deficits in the lower limbs, as well as bowel and bladder dysfunction. The neurosurgeon advised immediate decompressive laminectomy to decrease the risk of permanent neurologic deficits. The prone position was requested to allow optimal surgical access.

Recently, Kathirgamanathan et al. described successful lumbar disc surgery in the lateral position in a woman at 33 weeks gestation without intraoperative fetal monitoring. ${ }^{6}$ The consulting neurosurgeon in our case expressed that lateral positioning would make the surgery technically difficult and increase the duration of surgery and the risk of bleeding. Prone positioning and the risk of premature labour in the perioperative period were discussed with the obstetrician. It was the obstetrician's opinion that it would be difficult to monitor the fetal heart rate and uterine activity in the prone position, and even more difficult to perform an emergency delivery if required. At 35 weeks gestation the obstetrician and neonatologist agreed that it was reasonable to deliver the fetus by Cesarean delivery first. Delivery of the gravid uterus would facilitate positioning and decrease the risk of epidural bleeding during the decompression laminectomy. Also, the fetus would be spared radiation exposure during the laminectomy.

General anesthesia was the most practical option due to the need for two surgeries in two different positions, the potential for a lengthy duration, and bleeding. Epidural anesthesia has been reported for three cases of lumbar discectomy in early pregnancy by Brown and Levi. ${ }^{1}$ Potential advantages include less bleeding, better hemodynamic stability, postoperative analgesia, and less postoperative nausea and vomiting. However, spinal and epidural anesthesia in severe cases of spinal stenosis are associated with an increased risk of new neurological complications. ${ }^{7}$

The risks of maternal awareness, neonatal depression, and uterine atony with general anesthesia were discussed with the patient. To minimize neonatal depression, nitrous oxide and narcotics were avoided until after delivery. Sevoflurane was maintained at an end-tidal concentration of 1 MAC pre-delivery to avoid maternal awareness, and then decreased to 0.7 MAC with $60 \%$ nitrous oxide after delivery to decrease risks of uterine atony and bleeding.

The potential for difficulties with airway management was reviewed with the patient preoperatively. Examination of the patient's airway was reassuring in context of her gravid state. However, we were concerned about the potential for airway edema and post-extubation airway compromise resulting from the combined effects of the gravid state, prone positioning and parenteral fluid administration. There are several case reports documenting significant airway edema occurring in surgeries in the prone position. ${ }^{8-10}$ Szabo et al. reported a significant increase in laryngeal edema in patients undergoing surgery in the prone position as compared with the supine position, for operations lasting more than thee hours. ${ }^{11}$ BhavaniShankar et al. documented airway changes occurring in a parturient after fluid administration during Cesarean hysterectomy. ${ }^{12}$ Fortunately, the amount of bleeding was modest, and the cumulative volume of crystalloid infused was only $2.5 \mathrm{~L}$. The precaution of direct laryngoscopy at the end of the surgery revealed no evidence of edema, and the patient's trachea was extubated without placement of a tube exchanger, which was immediately available.

The potential for major bleeding, both surgical and postpartum, remained another important anesthetic consideration. The average blood loss associated with uneventful Cesarean delivery is between 500-1000 $\mathrm{mL}$. This blood loss is usually compensated by the physiologic increase in blood volume during preg- 
nancy and the autotransfusion of blood from the contracting uterus. Pregnant women have a $5-10 \%$ risk of postpartum bleeding secondary to four main causes: uterine atony, retained products of conception, coagulation abnormality, or trauma to the uterus. $^{13}$ These factors should be considered during any surgery in the immediate postpartum period. In our case there was mild uterine atony after delivery which responded to uterine massage and oxytocin.

Oxytocin can reduce the risk of postpartum bleeding by $40 \%{ }^{13}$ According to the Society of Obstetricians and Gynecologists of Canada guidelines, an effective oxytocin protocol includes giving $5 \mathrm{U}$ iv as a bolus and $10-20 \mathrm{U} \cdot \mathrm{L}^{-1}$ iv drip at $100-150 \mathrm{~mL} \cdot \mathrm{hr}^{-1}{ }^{13} \mathrm{We}$ continued the oxytocin infusion prophylactically during the laminectomy, as in the prone position it would have been difficult to monitor for uterine atony. The radial arterial line was placed to allow early detection of hypotension secondary to bleeding.

Blood loss can be severe during spine surgery, especially with multiple levels of decortications and prolonged surgeries. ${ }^{14}$ In this case only one spinal level was involved, but because the epidural veins would be engorged in the immediate postpartum period, we considered the laminectomy to be a significant risk factor for bleeding. Brown and Brookfield used a cell-saver while performing a lumbar discectomy after Cesarean delivery. ${ }^{5}$ We did not have a cell-saver available at the time. However, we took care to optimize the prone position so that there was little pressure on the patient's abdomen and uterus, and blood products were readily available.

In conclusion, with a cooperative multidisciplinary team approach and careful risk-benefit analysis, combined Cesarean delivery and posterior laminectomy and discectomy were successfully carried out under general anesthesia in a parturient at 35 weeks-gestation.

\section{References}

1 Brown MD, Levi AD. Surgery for lumbar disc herniation during pregnancy. Spine 2001; 26: 440-3.

2 Ashkan K, Casey AT, Powell M, Crockard HA. Back pain during pregnancy and after childbirth: an unusual cause not to miss. J R Soc Med 1998; 91: 88-90.

3 Timothy J, Anthony R, Tyagi A, Porter D, van Hille PT. A case of delayed diagnosis of cauda equina syndrome in pregnancy. Aust N Z J Obstet Gynaecol 1999; 39: 260-1.

4 Reibani-Kermani $H$. Cauda equina syndrome in pregnancy. Arch Iranian Med 2003; 6: 146-8.

5 Brown MD, Brookfield KF. Lumbar disc excision and cesarean delivery during the same anesthesia. J Bone
Joint Surg Am 2004; 86-A: 2030-2.

6 Kathirgamanathan A, Jardine AD, Levy DM, Grevitt $M P$. Lumbar disc surgery in the third trimester - with the fetus in utero. Int J Obstet Anesth 2006; 15: 1812.

7 Yuen, E, Layzer RB, Weitz SR, Olney RK. Neurological complications of lumbar epidural anesthesia and analgesia. Neurology 1995; 45: 1795-1801.

8 Sinha A, Agarwal A, Gaur A, Pandy CK. Oropharyngeal swelling and macroglossia after cervical spine surgery in the prone position. J Neurosurg Anesthesiol 2001; 13: 237-9.

9 McAllister RG. Macroglosia - a positional complication. Anesthesiology 1974; 40: 199-200.

10 Ellis SC, Bryan-Brown CW, Hyderally H. Massive swelling of head and neck. Anesthesiology 1975; 42: 102-3.

11 Szabo M, Denman W, Marota J, Robert J. Evaluation of airway edema in patients operated on in the prone position. J Neurosurg Anesthesiol 1997; 9: 380.

12 Bhavani-Shankar K, Lynch EP, Datta S. Airway changes during cesarean hysterectomy. Can J Anesth 2000; 47: 338-41.

13 Schumrmans N, MacKinnon C, Lane C, Etches D. Prevention and management of postpartum hemorrhage. J Soc Obstet Gynaecol Can 2000; 22: 271-81.

14 Nuttall G, Horlocker TT, Santrach PJ, Oliver WC Jr, Dekutoski MB, Bryant S. Predictors of blood transfusions in spinal instrumentation and fusion surgery. Spine 2000; 25: 596-601. 